This report was prepared as an account of work sponsored by an agency of the United States Government. Neither the United States Government nor any agency thereof, nor any of their employees, makes any warranty, express or implied, or assumes any legal liability or responsibility for the accuracy, completeness, or usefulness of any information, apparatus, product, or process disclosed, or represents that its use would not infringe privately owned rights. Reference herein to any specific commercial product, process, or service by trade name, trademark, manufacturer, or otherwise does not necessarily constitute or imply its endorsement, recommendation, or favoring by the United States Government or any agency thereof. The views and opinions of authors expressed herein do not necessarily state or reflect those of the United States Government or any agency thereof.

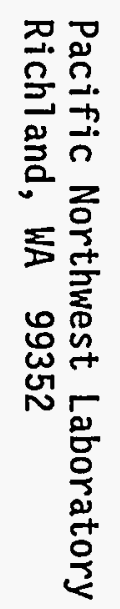
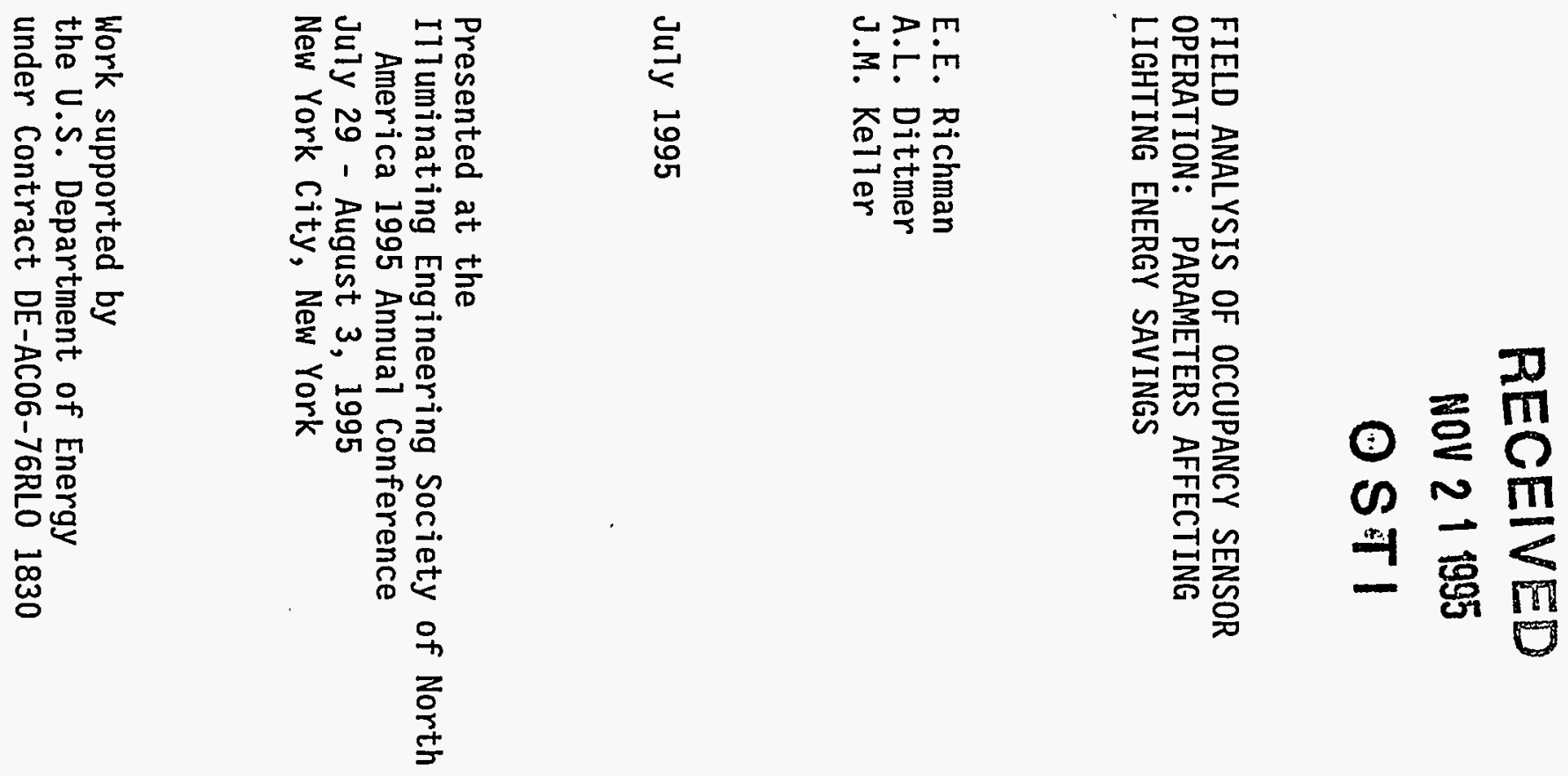


\title{
Field Analysis of Occupancy Sensor Operation: Parameters Affecting Lighting Energy Savings
}

\author{
E. E. Richman \\ A. L. Dittmer \\ J. M. Keller
}

Authors' affiliation: Pacific Northwest Laboratory, Richland, WA.

\section{Introduction and Objective}

Sensors that detect occupancy have been used for many years to monitor or control various mechanical and energy-related functions, including lighting operation. As energy-saving devices, occupancy sensors are well suited to reduce lighting use whenever spaces are unoccupied. The potential energy savings from occupancy lighting control depends on several factors related to the building space, occupants, and equipment used in the space. Two major factors are 1) potential "wasted-light" hours (the time lights remain on in an unoccupied space) associated with occupant characteristics and job functions, and 2) specific lighting control equipment settings and sensitivities. In all occupancy lighting control situations, the operation of the lighting by occupants is the most dominant factor in determining actual lighting energy savings. This factor is also the most variable and hardest to assess. The operating characteristics of specific lighting control equipment are also a major and often unknown factor in potential lighting savings. Most occupancy sensors use some type of delay timer to account for small occupant movements that may not be noticed by the sensor.

The actual lighting energy savings attributable to these factors is not well known. Information is available in manufacturer-provided product literature, published reports, and articles that describe the designed operating characteristics of various types of occupancy sensors. Some evaluation of occupancy sensor operational characteristics has been performed in field-like settings. ${ }^{1}$ Many case studies also exist that report actual or estimated savings attributable to installation of multiple occupancy sensors for entire facilities or specific rooms. ${ }^{23,4,5}$ What historically has not been known is the actual savings associated with specific types of individual sensor installations and the parameters that affect these energy savings. New emerging test equipment provides the capability to perform individual space testing on a case-by-case basis. This kind of space testing is used sometimes in trial runs before installation of large groups of sensors. However, small samples of specific locations cannot always provide an accurate estimate of savings achievable from an entire facility retrofit. When many installations in a variety of spaces are planned, a general indication of effectiveness in . each space type is needed. This information allows the user to identify only those spaces that will provide energy savings from occupancy sensor installation.

A field study of the actual lighting savings achievable from occupancy sensor use was performed by Pacific Northwest Laboratory (PNL) for the U.S. Department of Energy (DOE) on the Hanford Site near Richland, Washington. The study involved two seperate field assessments. The objective of the first test was to assess and effectively quantify the potential "wasted-light" hours associated with different occupant and space types associated with occupancy sensor control installations. These 
quantities are the primary factor in determining actual lighting energy savings associated with occupancy lighting control. The second test was conducted to explore the potential additional savings from more sensitive sensor equipment or better equipment adjustment that might reduce the need for delay timers. This information provides quantitative insight into the energy savings lost because of the limitations of current sensing equipment.

\section{Field Data Collection}

\section{Sample Spaces and Characteristics}

The spaces that made up the study sample represented a cross section of the space types found in office and laboratory facilities. The spaces were selected from facilities occupied by subcontractors to the DOE at the Hanford Site. These facilities represent, in form and function, the range of lighted, occupied facility spaces in most buildings. Spaces were also selected where the occupants and activities in the space were considered to be fairly stable. Spaces with odd configurations or mixed uses usually were not selected. Although these space types do exist in all buildings, their numbers are relatively few compared to standard spaces.

Testing was completed in eight separate buildings. A total of 154 sample test periods comprising more than 54,700 hours of test time were completed for potential use in the study. A small percentage of these sample test periods were removed from the analysis because conditions adversely affected the individual test results, including failed lighting sources and inappropriate sensitivity adjustments. The remaining 141 samples with more than 50,400 test hours were used in the analysis. Descriptions and quantities of the spaces and occupant types making up these 141 samples are shown in Table 1. For each space or occupant type, the number of spaces used in the testing and the total number of test hours is shown.

Table 1-Building space and occupant type Samples

\begin{tabular}{|c|c|c|c|}
\hline Space or & & Sample & Total \\
\hline Occupant Type & Description & Number & Test Hours \\
\hline Conference & Conference Room & 13 & 5,383 \\
\hline Copy & Photocopy and/or Mail Room & 9 & 3,186 \\
\hline $\mathrm{Lab}$ & Laboratory Without Office Area & 12 & 3,909 \\
\hline Library & Library (small) Typically not Manned & 4 & 1,349 \\
\hline Lunchroom & Lunchroom or Break Room & 13 & 5,711 \\
\hline Restroom & Restroom or Restroom/Locker & 10 & 3,616 \\
\hline Storage & Storage Room & 3 & 980 \\
\hline Training & Training Room/Classroom & 1 & 333 \\
\hline Administrative & Administrator - Program or Finance & 22 & 7,345 \\
\hline Clerical & Clerk - Financial or Technical & 3 & 955 \\
\hline Technical & Engineer/Scientist/Economist/Architect & 36 & 11,988 \\
\hline Managerial & Manager/Group Leader & 8 & 3,339 \\
\hline Secretarial & Secretary/Receptionist & 7 & $2,343^{\circ}$ \\
\hline
\end{tabular}

For each sample space, a complete set of space and occupant characteristics data was recorded for use in determining any relational effects on potential lighting savings. These data were collected 
at the time the sensor equipment was installed. Characteristics that may have an affect on lighting operation and savings potential, such as occupant type and number, function of space, window area, lighting count, and occupant number and type, were entered in spreadsheets with the data collected from the sensor equipment.

\section{Occupant and Space Type Test Design}

The test was conducted using a lighting logger with interactive circuitry for use with a sensor, a companion ultrasonic motion sensor, and a stand-alone lighting logger. A total of 11 sets of similar equipment were utilized during data collection.

The lighting logger and companion ultrasonic sensor used in the analysis are products of Mytech Corporation. The sensor units included an early version Model OA-1000 test kit containing a Model EM-300 lighting logger with companion sensor, and a later Model EAK-101 analyzer kit containing a Model EM-301 lighting logger and companion sensor. Both models are functionally the same and have similar operating characteristics. Equipment from other manufacturers is available to perform equivalent tests. The sensor units are designed to hang from the grid members of any grid ceiling system using a special clip provided with the unit. Concerns over possible asbestos in the ceiling area of one of the test facilities prohibited any movement of the panels to install the clip. For these installations, a bracket attaching to the very bottom of the grid support was fashioned for each of the units. In other building spaces, a variety of ceiling grid mount and magnetic cabinet and wall mount configurations were used.

The early model sensor unit provides for attachment of the companion logger to the sensor unit. In our study, it was sometimes imperative that the logger be installed inside a fixture. The sensor units were modified with an adapter cord from the sensor to companion logger. The later model was designed for remote logger placement and no adjustment was required. A 24-V power supply plugged into a standard $120-\mathrm{V}$ socket provided power to the sensor unit and completed this setup.

In the operating mode, the lighting logger counts time increments in tenths of an hour whenever the photocell reads sufficient light levels and the sensor reads no motion (open-closed contact signal to the logger) for a specified delay period. This delay period is used to ensure that lights are not turned off when occupants are making small or infrequent movements. The resulting time values are considered to be wasted-light hours, indicating the potential savings from improved lighting control. The time delay for these tests was set between 5 and 8 minutes, which can be considered a reasonable effective energy saving setting. Half of the companion loggers were supplied with a sensitivity adjustment used to capture appropriate light-on levels. The sensors were equipped with a signal sensitivity setting, allowing for motion-sensing signal adjustments in case of traffic in nearby areas that may cause false occupancy readings. Each sensor also was equipped with a timer sensitivity adjustment used to set the length of time the unit waited before starting to count wasted-light hours after sensing no motion. This adjustment ensures that lights do not go off when occupants are infrequently making large motions (e.g., reading).

The stand-alone lighting logger used in the analysis was a Model 100 lighting logger produced by Pacific Science and Technology. While in operation, the logger records tenths-of-an-hour increments based on photocell indication of light. These units were supplied with sensitivity adjustments to provide effective light-on time readings. To verify proper equipment operation, this logger was attached in or near a subject lighting fixture to record total light-on time to compare with the other logger readings. 
Each sample space was monitored for a 2- to 4-week period. At the end of each period, the time readings on the two loggers were recorded and reset, and a post-test check of each unit's operation was made to ensure the appropriateness of the data. The recorded data also were compared with expected values to verify accuracy.

\section{Equipment Time-Delay Test Design}

The test equipment used to assess the effects of better time-delay adjustment consisted of an ultrasonic sensor test unit and a voltage datalogger. Two sets of identical equipment were used for this test.

The sensor unit came from the newer Model EAK-101 analyzer kit from Mytech. The datalogger was a Model XT-107 Voltage/Current/Temperature unit produced by ACR Systems Incorporated (ACR). This datalogger can read a variety of inputs, including $0-\mathrm{V}$ to $10-\mathrm{V}$ input. Because the sensor unit outputs only an open-close signal, an interim voltage supply was used to provide a measure of occupancy based on the open-close signal from the sensor. For these tests, a 9$\mathrm{V}$ battery was placed in a circuit between the sensor and datalogger. The datalogger stores timeseries voltage and outputs the data to ACR software or other types of spreadsheets.

For this test, the timer setting on the sensor unit was set to the minimum value of approximately 5 seconds to identify exact occupancy periods without the effects of timer delay. The unit was located and adjusted so that very small movements by occupants would be detected to ensure collection of the most accurate occupancy data, with no false readings. The sensor unit was placed close to the occupant's normal sitting position, and/or the sensitivity was raised to maximum and the doors to the space were kept closed during the test period.

The equipment test used a subset of the spaces used in the occupant and space type test. Each test was conducted over a 24- to 72-hour period to capture typical operating characteristics. Each set of data was compared to known schedules to verify accuracy.

\section{Analysis Process}

\section{Occupant and Space Type Analysis}

For each 2- to 4-week sample, the hours of wasted light (as recorded by the sensor/logger setup) were extrapolated to a full year using Equation (1).

$$
\text { YWHours }_{\text {Light }}=\text { WHours }_{\text {Light }} *\left[\frac{8760}{\text { Hours }_{\text {Equiq }}}\right]
$$

where $\quad$ YWHours $_{\text {Light }}=$ total yearly wasted-light hours

WHours $_{\text {Ligh }}=$ wasted-light hours identified in the field test

$8760=$ available hours in a year

Hours $_{\text {Equip }}=$ total hours the equipment is installed during the field test.

All sets of sensor equipment were set up and removed on the same day of the week and within several hours of each other to minimize any skewing based on nonexact 2- to 4-week periods.

Sample periods with holidays were identified but not adjusted for working/nonworking hours. The 
effects of both of these conditions was considered negligible compared to the other variables in the analysis.

To identify factors affecting energy usage, the differences in wasted-light hours for each space characteristic were compared. The following characteristics are considered to have possible effects on lighting operation and were included in the analysis:

- availability of daylight

- space type (e.g., small office, large office, copy room, conference room)

- occupant type/function (e.g., engineering, administration)

- number of occupants.

The applicable data for each of these characteristics were compared and/or plotted where appropriate to visually determine any apparent trends. Those characteristics that exhibited trends were further explored to assign wasted-light hour values to appropriate space configurations and characteristics. The result of this analysis was a set of wasted-light hour values associated with various occupant and/or space conditions that will form the basis for the assessment of cost-effective lighting control projects.

\section{Equipment Time-Delay Analysis}

With currently available lighting occupancy sensor equipment, the user can set the strength of the motion-sensing signal and the length of the time-delay function tied to switching off lights. This timedelay feature is useful when the strength of the motion-sensing signal must be set lower to avoid detection of occupants outside the desired building space (ultrasonic) or nonoccupant heat sources within the building space (infrared).

The time-delay feature can also affect the quantity of lighting hours saved by the equipment. Whenever the space is vacant, the time allowed before turning the lights off affects the total amount of saved lighting hours. The difference in savings depends on the difference in the timer setting as well as the number of stops or light-off cycles made by the equipment. The number of cycles are directly dependent on the occupant's work function and style, and are not affected by the time-delay setting.

To assess these effects, a set of tests was conducted to quantify the differences in potential lighting savings associated only with timer setting adjustment. Each test was conducted with identical equipment and setup arrangement. The data collected in each test were time-series streams of voltage readings taken at 8-second sampling periods and averaged over 56-second periods by a datalogger. , The accompanying sensor took occupancy readings every 5 to 8 seconds and provided an open-close contact signal that produced a voltage input to the datalogger. This stream of data was in voltages from 0 to $9 \mathrm{~V}$, indicating (to a few seconds) the length and frequency of occupied and unoccupied periods. A set of time filters that calculate potential wasted-light hours based on the length and frequency of collected data was applied to each data set to quantify the potential savings associated with various time-delay settings in each situation. The results of this test indicated the potential variability in lighting savings based on timer setting.

\section{Analysis and Results}

\section{Occupant and Space Type}


Lighting needs are determined by human occupancy and activity. Human behavior is therefore considered a primary space characteristic, having an effect on potential lighting energy savings associated with lighting control. This characteristic was the first one explored in this analysis. Data points corresponding to spaces with permanent occupants were used and are shown in Figure 1.

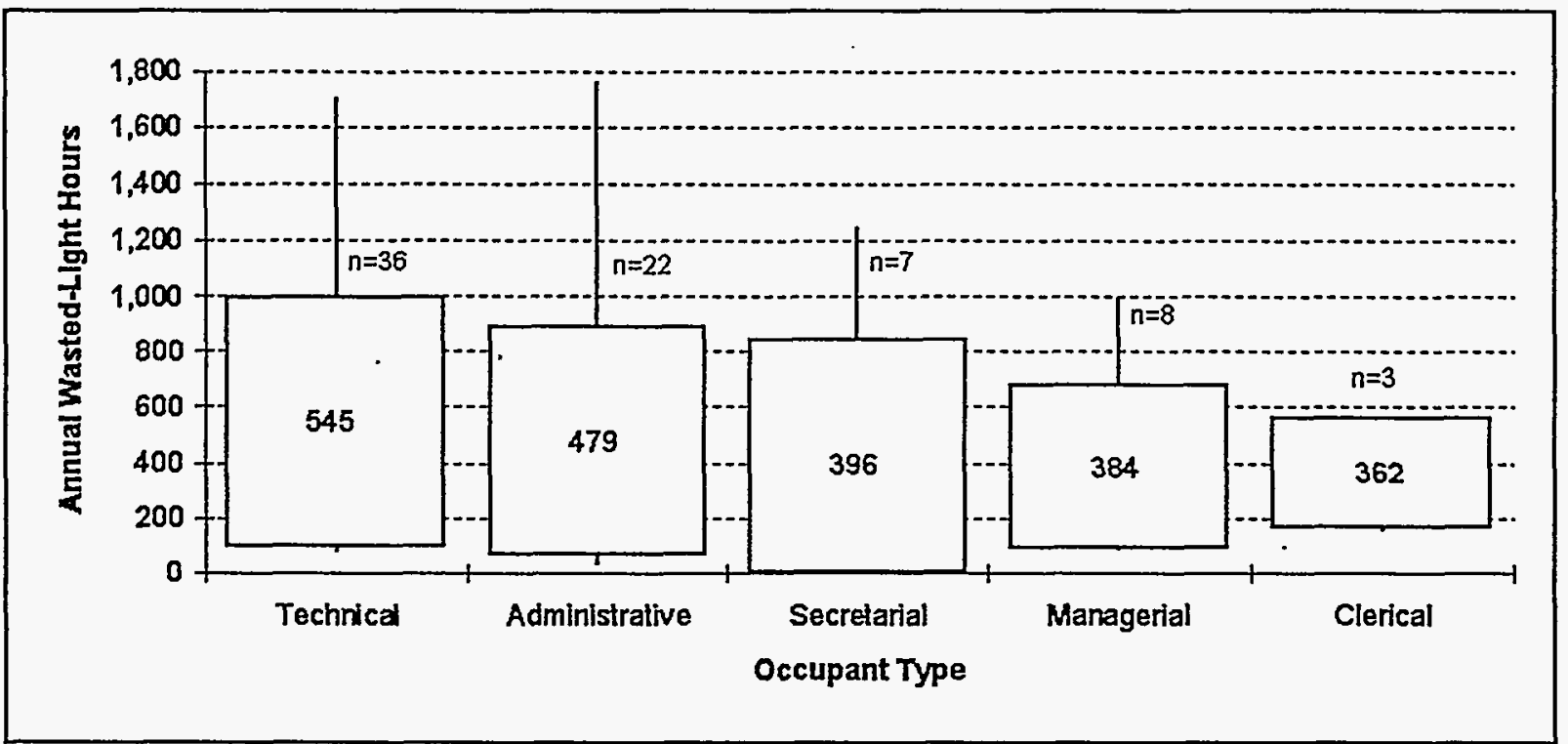

Figure 1. Annual Wasted-Light Hours by Occupant Type

A "box and whisker" plot is used to show the range of wasted-light values for each occupant type group. The "whiskers" indicate the minimum and maximum values for each group, the top and bottom of the box indicate plus or minus one standard deviation, and the mean value is printed in each box at the mean point in the plot. These plots indicate the form and magnitude of variability or scatter associated with potential energy savings within each group. Also included with each plot are " $n$ " values, indicating the number of samples used to produce each plot. This plot indicates that technical and administrative staff exhibit higher potential lighting savings than secretarial, managerial, and clerical staff. The plot also shows a very slight increase (mostly high values) in the variability of actual potential savings associated with technical and administrative staff. Although the differences in the mean potential savings between staff appear small on the plot, they represent potentially significant values. The potential savings difference between clerical and technical staff mean values is equivalent to an approximately $50 \%$ increase over the clerical staff value. Variability indicates truelife conditions and each space will exhibit different savings potential. The mean values can be considered useful only when multiple installations are planned or considered.

The second primary space type characteristic considered in this analysis was the possible effect of daylighting availability on potential energy savings. To assess potential savings associated only with daylighting, companion sets of data were used from the two largest occupant type categories. The other categories had sample numbers considered too small to produce usable results. If a similar trend was evident between the groups, then an effect could be implied. Figure 2 shows the box and whisker plots for these occupant types. The plots show no clear trend that can be attributed to daylighting, although effects resulting from daylighting availability exist. 


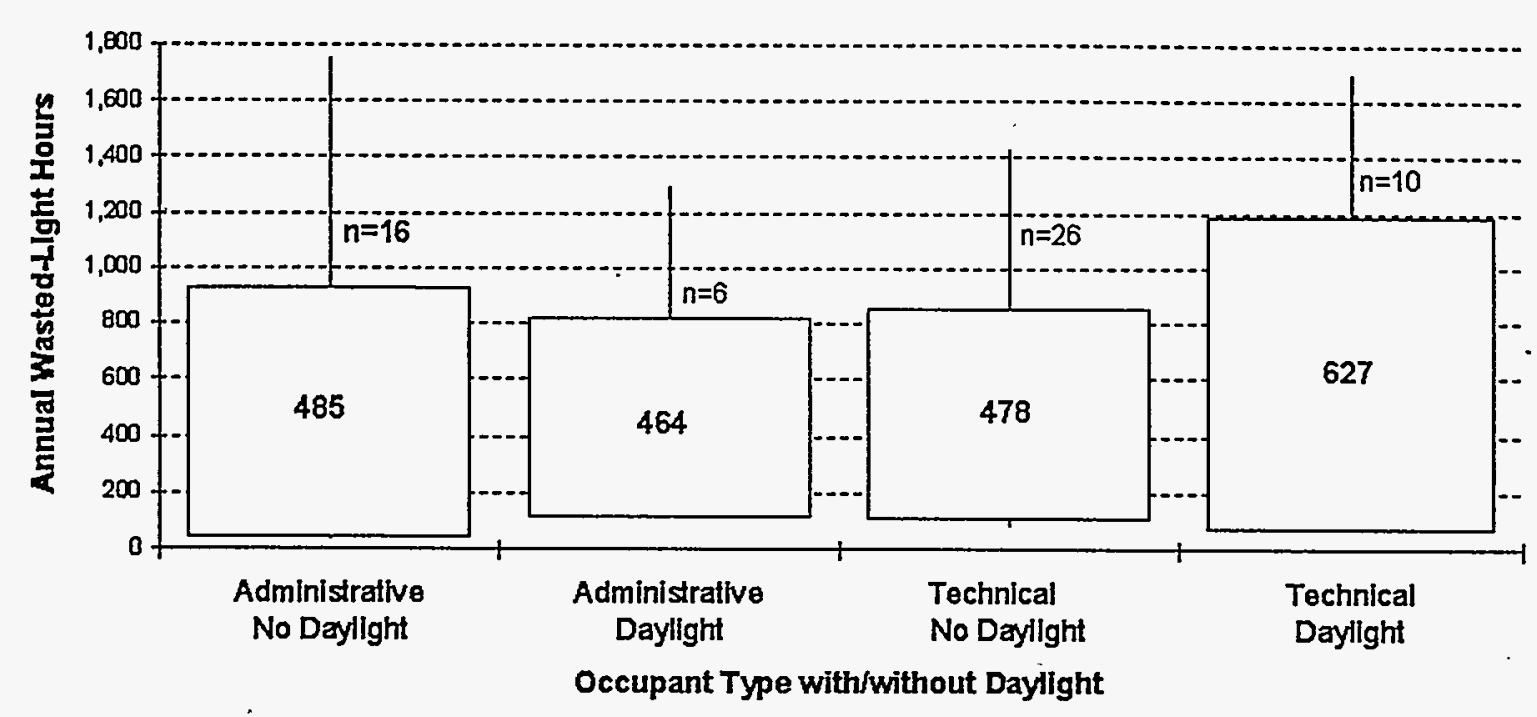

Figure 2. Annual Wasted-Light Hours by Occupant Type With/Without Daylight

A third characteristic explored in this analysis was the number of occupants in a particular lighted space shown in Figure 3. The fact that more than one occupant uses a space may affect lighting operation or the number of opportunities to save energy because of increased occupancy time. To avoid including other effects from multiple occupant types that may mask the effect of occupant count alone, the two largest data sets were split into single and multiple groupings.

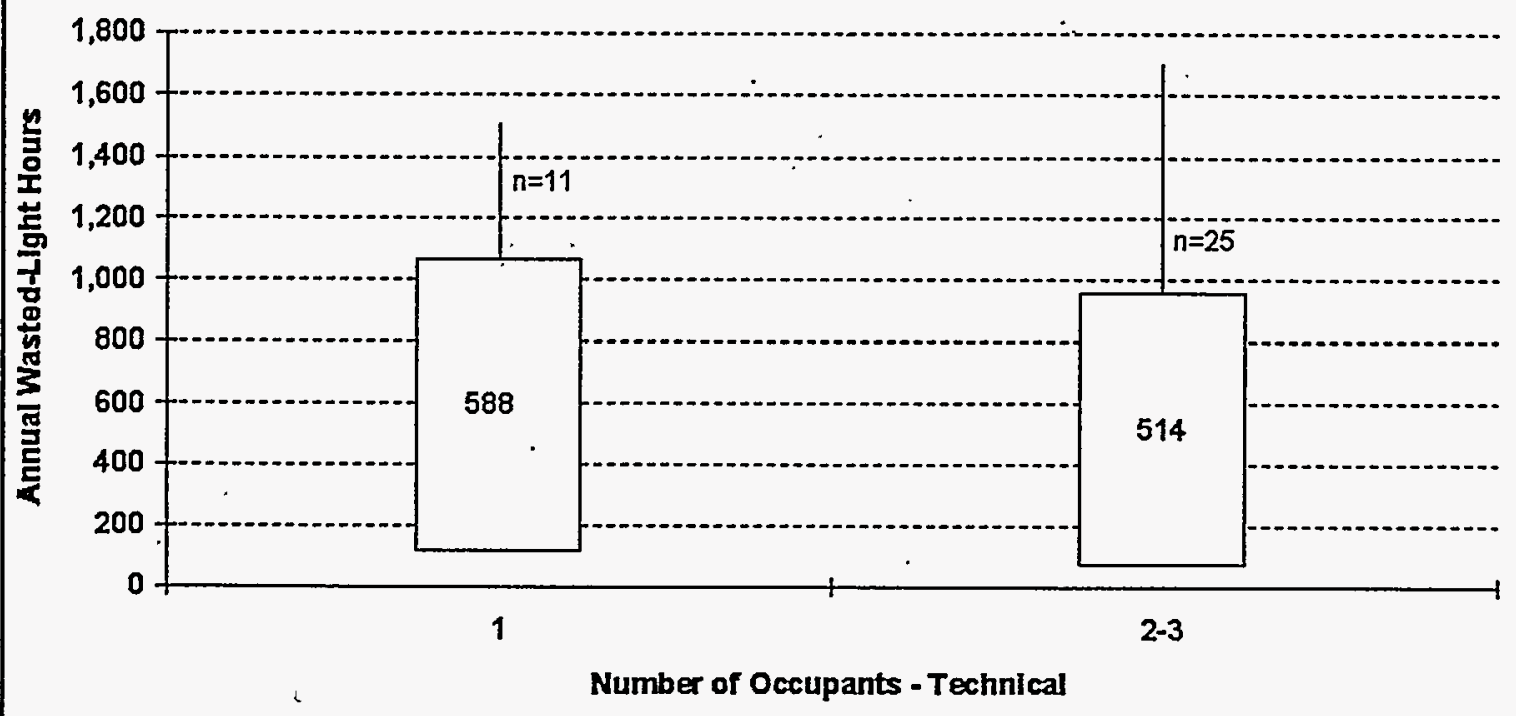

Figure 3. Annual Wasted-Light Hours by Number of Technical Occupants 
Figure 3 shows a decrease in potential lighting savings when multiple technical occupants are in one space. This is attributed to the staggared use of the space associated with more than one opccupant. The spaces with one occupant appear to have a $14 \%$ increase in savings potential over those with multiple occupants. The spread of actual values in both categories is very wide and the mean values shown must be considered useful only when dealing with multiple spaces. Similar data for administrative occupants is shown in Figure 4, showing a smaller effect in savings potential for single-occupant spaces, with only an $11 \%$ increase.

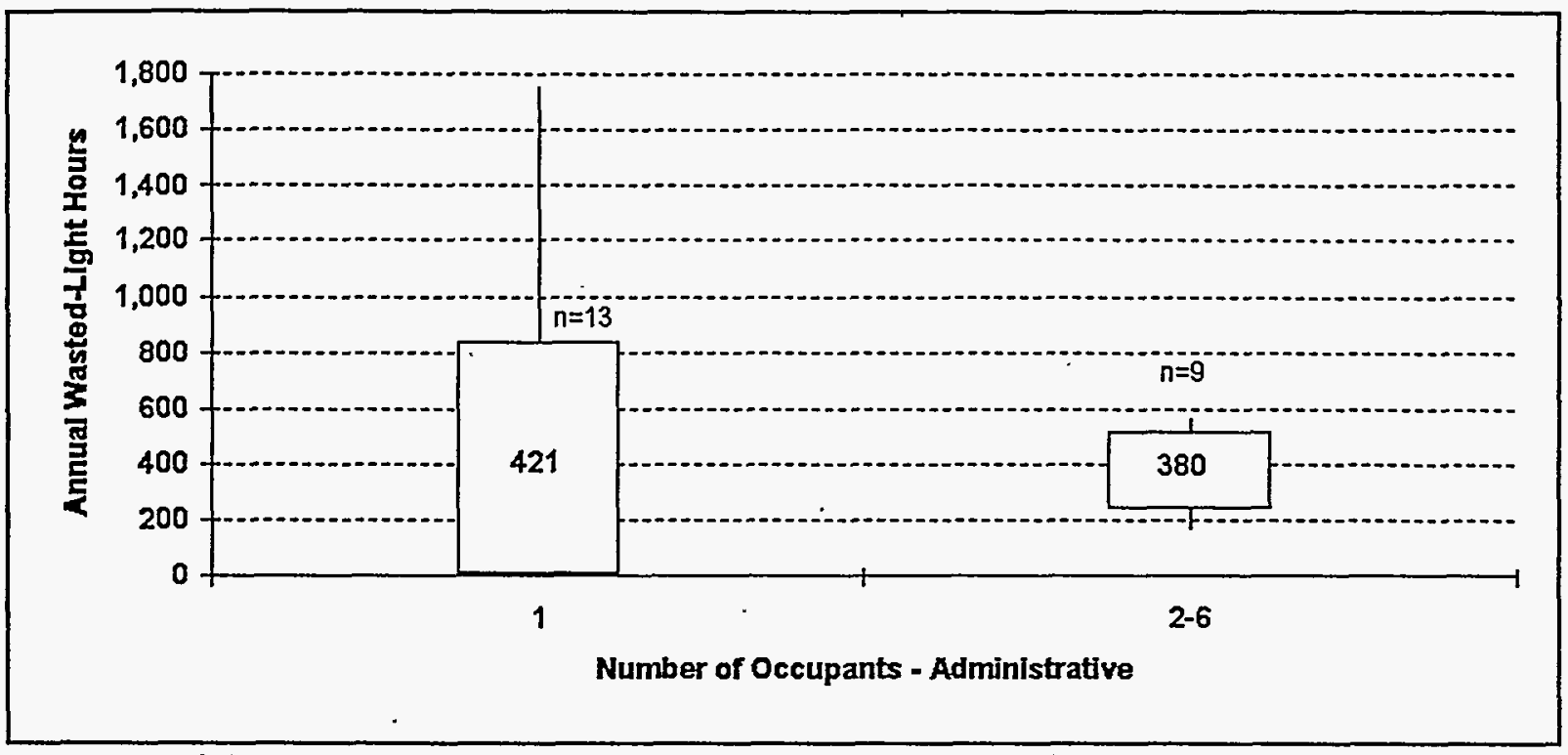

Figure 4. Annual Wasted-Light Hours by Administrative Occupants

The final characteristic explored in this analysis was the difference in room type and function. Lighting control in permanently occupied spaces is affected by the occupants. Spaces that do not have permanent occupants experience lighting control based on temporary occupant motivation. Figure 5 shows box and whisker plots for each of the space types that generally have no permanent occupants. Conference and training spaces have little savings potential. These spaces are actually temporarily owned by the occupants; thus, the lights are more likely to be controlled manually. The library spaces in the sample are generally small-specific reference storage areas not occupied by a materials custodian. Thus, these spaces are operated similarly to storage areas where materials are retrieved on a case-by-case basis. These spaces are also temporarily owned and the potential savings is relatively low. A final space type group, at the high end of potential savings, includes copy rooms, lunchrooms, unoccupied laboratory spaces, and restrooms. These spaces are all characterized as being generally unowned by any one person at any time. They are considered public spaces, and the lighting is usually not controlled by most users. As with the effects of the other characteristics, the wide variability of the individual data points in the groupings must be considered.

The results of this analysis are the calculated mean wasted-light hours shown in Table 2. The value of \pm one standard deviation from the mean is included to present a range of values associated with each mean. If a single space or only a few spaces are being considered, these ranges can be useful in understanding the possible variance in actual savings potential. Because the test equipment 


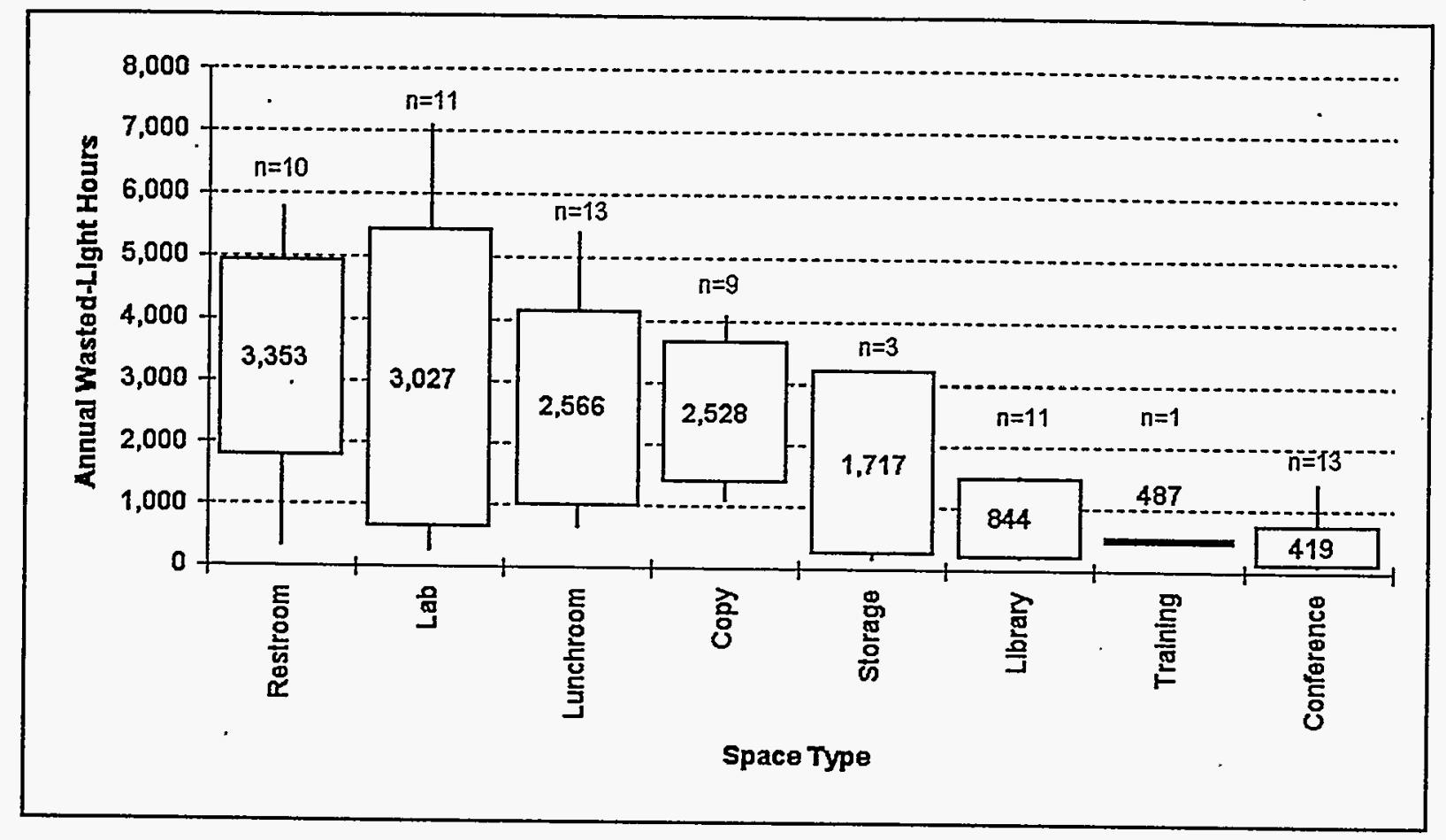

Figure 5. Annual Wasted-Light Hours by Space Type

was set at a timer delay of between 5 and 8 minutes (less than the 10- to 20-minute factory setting), these values are considered somewhat conservative:

Table 2-Wasted-light hours for occupant and space types

\begin{tabular}{lrr} 
Space or Occupant Type & Wasted-Light Hours & + Standard Deviation \\
\cline { 2 - 3 } Restroom & 3353 & 1580 \\
Lab & 3027 & 2408 \\
Lunchroom & 2566 & 1579 \\
Copy & 2528 & 1132 \\
Storage & 1717 & 1476 \\
Library & 844 & 648 \\
Training & 487 & 0 \\
Conference & 419 & 323 \\
Technical (2+ occup) & 514 & 446 \\
Technical (1 occup) & 588 & 477 \\
Administrative (2+ occup) & 380 & 140 \\
Administrative (1 occup) & 421 & 417 \\
Secretarial & 396 & 447 \\
Managerial & 384 & 295 \\
Clerical & 362 & 197
\end{tabular}




\section{Equipment Time Delay}

The testing and analysis performed on the time-delay adjustment of the sensor equipment provides insight into the importance of equipment adjustment at installation and during use. The timer adjustment determines how long the unit will wait after sensing no motion before turning lights off. This feature helps avoid inadvertently turning lights off when occupants are making movements too small for the sensor to read.

The analysis of this equipment feature is based on very precise occupancy data used to assess exact occupancy and no-occupancy periods. Several offices and other rooms were initially monitored, but some were found to be difficult spaces in which to acquire good data. The six test spaces that produced accurate data represented those used by technical ( 2 offices) and managerial occupants ( 2 offices), a restroom, and a copy/mail room.

The data from these six tests were recorded as time-series voltage readings indicating occupancy periods. Each set of raw voltage data was converted to occupancy period information. All weekend days were removed from the data to create data sets representing only occupied periods. The data were divided into 24-hour periods to ensure consistency between rooms.

For office spaces, persons popping their heads into a space to see if the occupant was present was not considered an occupied situation for these tests. If the sensor was actually controlling the lights, the lights would be off and it would be unnecessary to enter the space to determine if the occupant was present. For each incidence of this nature, the datalogger records 5 to 8 seconds of occupancy and may show a positive voltage reading for one 8-second sampling period. These readings cause average recorded values of less than $1.5 \mathrm{~V}$ in the 56 -second datalogger time interval. For this study, these intervals were not considered occupancy. Any activation of the sensor in the restroom or copy/mail room was considered occupancy because it is common for people to quickly move in and out of these spaces This is especially true in the copy/mail room, where a person can easily enter, retrieve mail from a box, and exit in 8 seconds.

When occupants remain still for periods greater than the 56-second reading time, a recorded 0 voltage reading may occur, indicating false unoccupancy. Given the accuracy of the test setup for this analysis, a false unoccupancy is unlikely. It is even more unlikely that these periods will last as long as 2 minutes, which can be considered a minimum setting in real applications of today's technology. Some short-term informal field testing was conducted on office spaces having occupancy sensor lighting control. In all cases where the timers were set at 2 minutes, the occupants experienced lights going off while in the space. Therefore, periods of apparent unoccupancy for less than 2 minutes will ultimately be considered not useful as potential lighting reduction time and possible false, unoccupied readings less than 2 minutes will not affect data quality. The result was a list, by space, of the length of the unoccupied period and the number of times that particular length of unoccupied period had occurred. Table 3 presents this calculated data for one of the office spaces. 
Table 3-Sample calculations of percent potential savings from different time delay settings

\begin{tabular}{|c|c|c|c|c|c|c|}
\hline \multirow[b]{2}{*}{$\begin{array}{l}\text { No. of } \\
\text { Minutes }\end{array}$} & \multirow[b]{2}{*}{$\begin{array}{c}\text { No. of } \\
\text { Occurrences }\end{array}$} & \multicolumn{5}{|c|}{ Cumulative Minutes Saved at: } \\
\hline & & $\begin{array}{l}\text { 20-Min } \\
\text { Setting }\end{array}$ & $\begin{array}{l}\text { 15-Min } \\
\text { Setting }\end{array}$ & $\begin{array}{l}\text { 10-Min } \\
\text { Setting }\end{array}$ & $\begin{array}{l}\text { 5-Min } \\
\text { Setting }\end{array}$ & $\begin{array}{l}\text { 2-Min } \\
\text { Setting }\end{array}$ \\
\hline 1 & 7 & - & - & - & - & - \\
\hline 2 & 4 & - & - & - & - & 0 \\
\hline 3 & 5 & - & - & - & - & 5 \\
\hline 4 & 3 & - & - & - & - & 11 \\
\hline 5 & 5 & - & - & - & 0 & 26 \\
\hline 6 & 3 & - & - & - & 3 & 38 \\
\hline 7 & 2 & - & - & - & 7 & 48 \\
\hline 8 & 2 & - & - & - & 13 & 60 \\
\hline 9 & 3 & - & - & - & 25 & 81 \\
\hline 10 & 1 . & - & - & 0 & 30 & 89 \\
\hline 12 & 1 & - & - & 2 & 37 & 99 \\
\hline 13 & 2 & - & - & 8 & 53 & 121 \\
\hline 14 & 2 & - & - & 16 & 71 & 145 \\
\hline 15 & 4 & - & 0 & 36 & 111 & 197 \\
\hline 16 & 1 & 0 & 1 & 42 & 122 & 211 \\
\hline 21 & 1 & 1 & 7 & 53 & 138 & 230 \\
\hline 22 & 2 & 5 & 21 & 77 & 172 & 270 \\
\hline 25 & 1 & 10 & 31 & 92 & 192 & 293 \\
\hline Per & ent Savings: & $<3 \%$ & $8 \%$ & $24 \%$ & $50 \%$ & $76 \%$ \\
\hline
\end{tabular}

To calculate the savings at a specific time setting, the length of the sensor time delay was subtracted from the length of each unoccupied period. For example, a space with a 15-minute unoccupied period equipped with a sensor set at a 10-minute time delay will result in 5 minutes of light savings. These savings were calculated for 2-, 5-, 10-, 15-, and 20-minute time-delay settings, with the amount of savings being summed for each time setting. Blank cells in Table 3 are periods when the space was not occupied long enough for the lights to turn off. At the bottom of the table are percentages of potential savings if the lights were turned off as soon as the occupant left the space (i.e., if a 0 -minute delay were possible, there would be $100 \%$ savings).

A set of histograms was developed to present the percentage of lighted unoccupied time in various time bins for each space. Figures 6 through 11 show the binned unoccupied periods for each space. The two technical staff samples (Figures 6 and 7) show that most of the unoccupied periods - are of short duration. In these cases, the standard timer setting (usually factory-set at 10 to 20 minutes) represents a large portion of each period. Therefore, the percentage of additional savings from reducing this delay is high. The unoccupied periods for managerial occupants are more varied, but are heavily represented by longer periods. In these cases, the standard timer settings represent a smaller portion of total unoccupied time, and therefore savings percentages are smaller. 


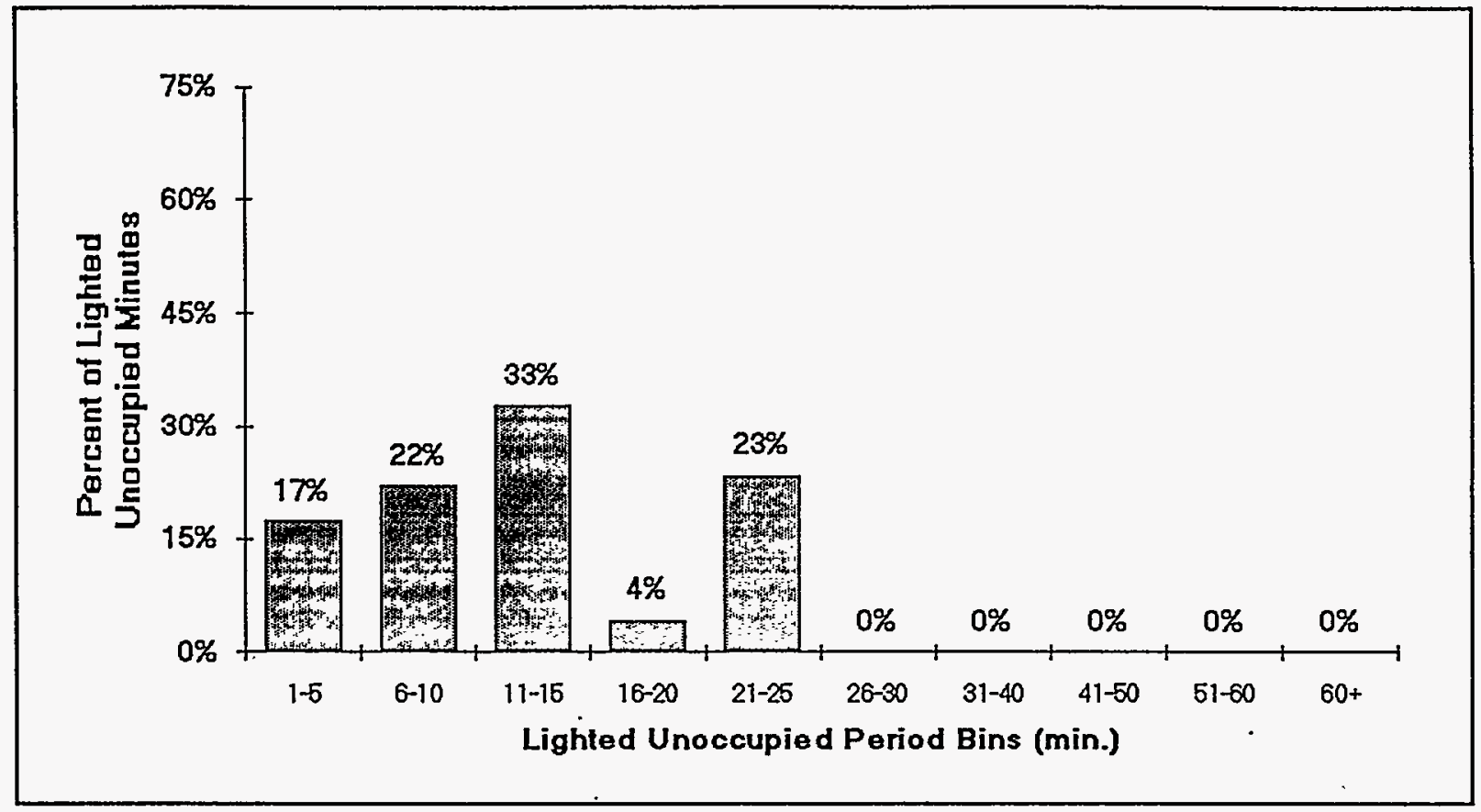

Figure 6. Percent of lighted unoccupied minutes for Technical Staff No. 1

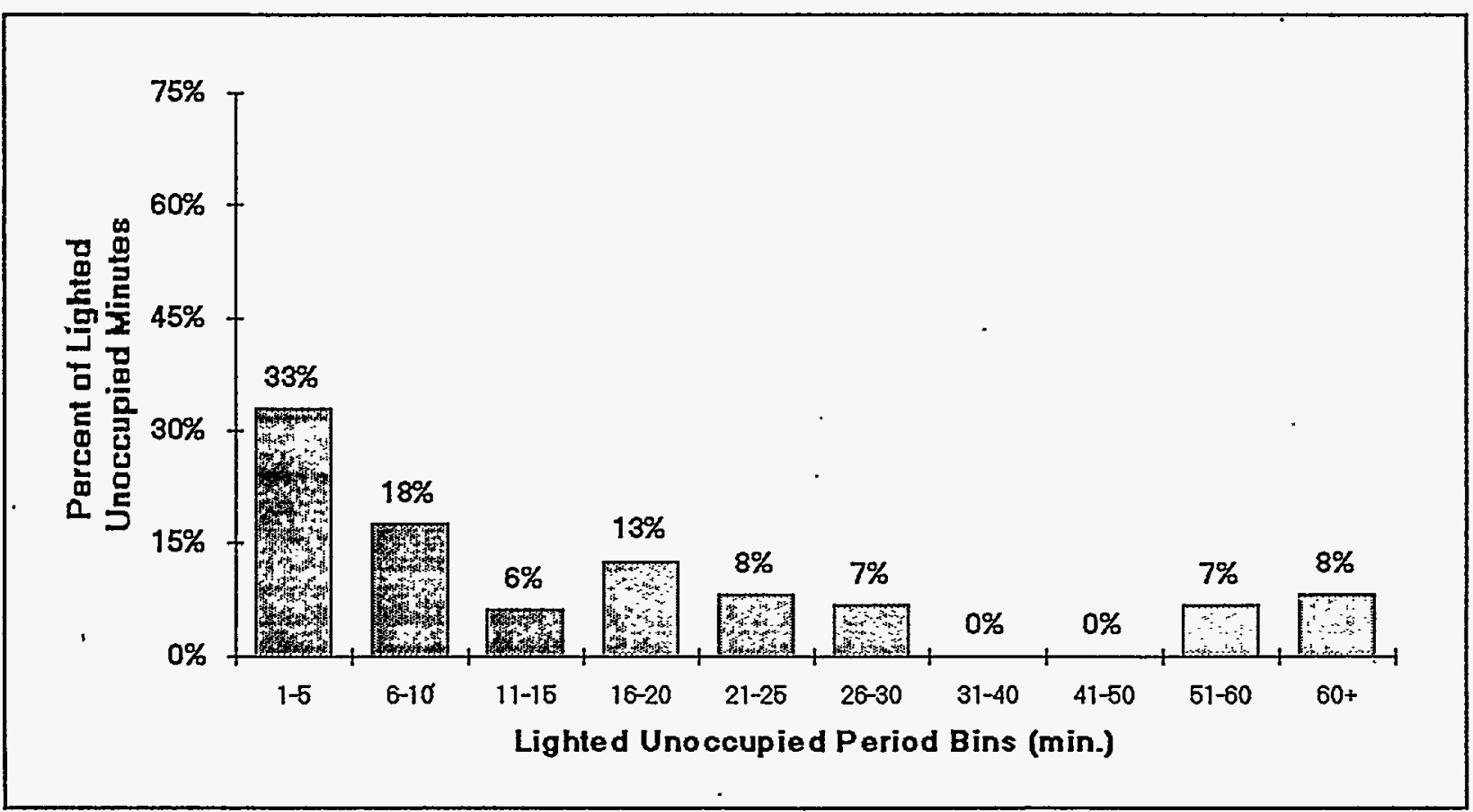

Figure 7. Percent of lighted unoccupied minutes for Technical Staff No. 2 


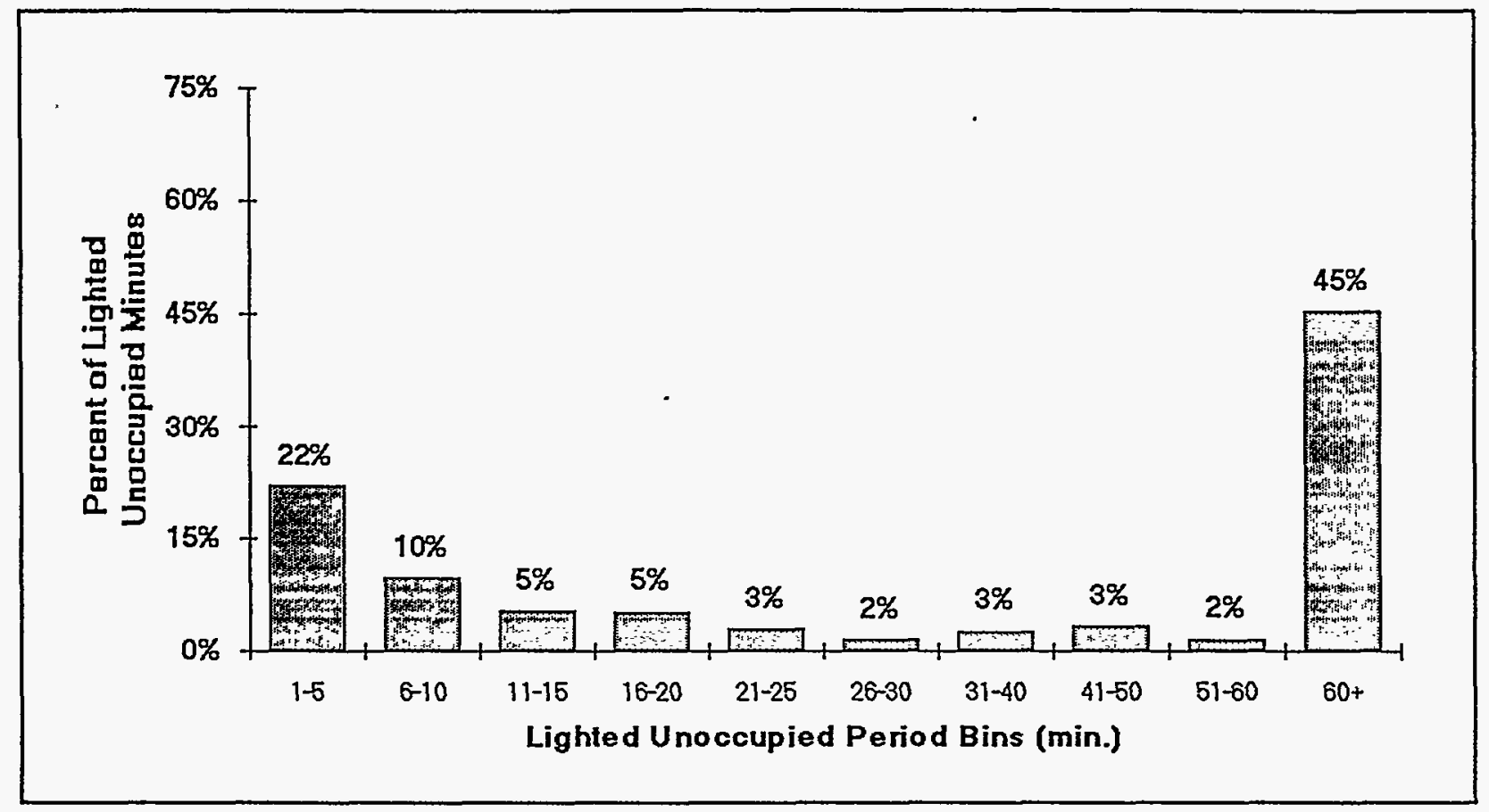

Figure 8. Percent of lighted unoccupied minutes for Manager No. 1

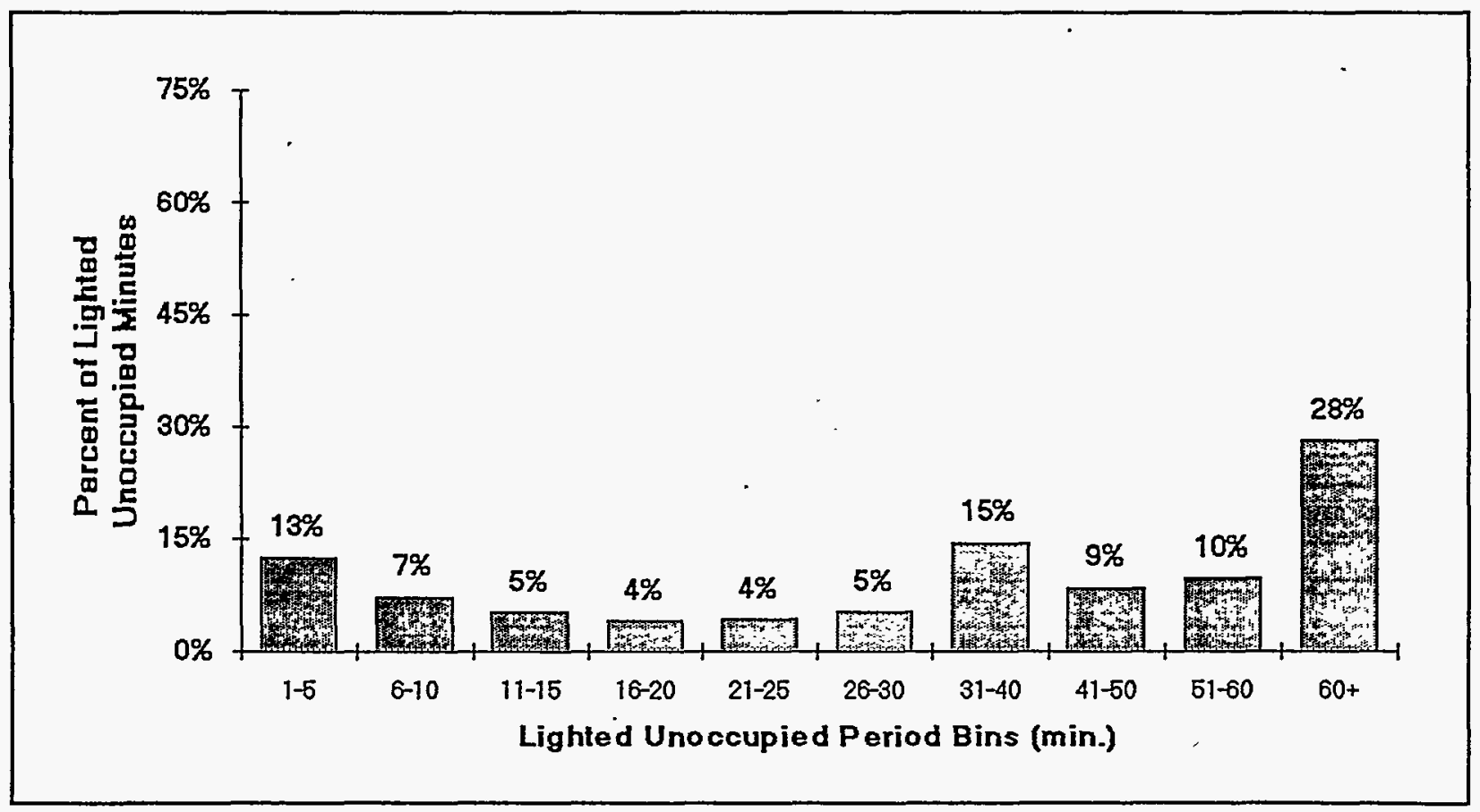

Figure 9. Percent of lighted unoccupied minutes for Manager No. 2 


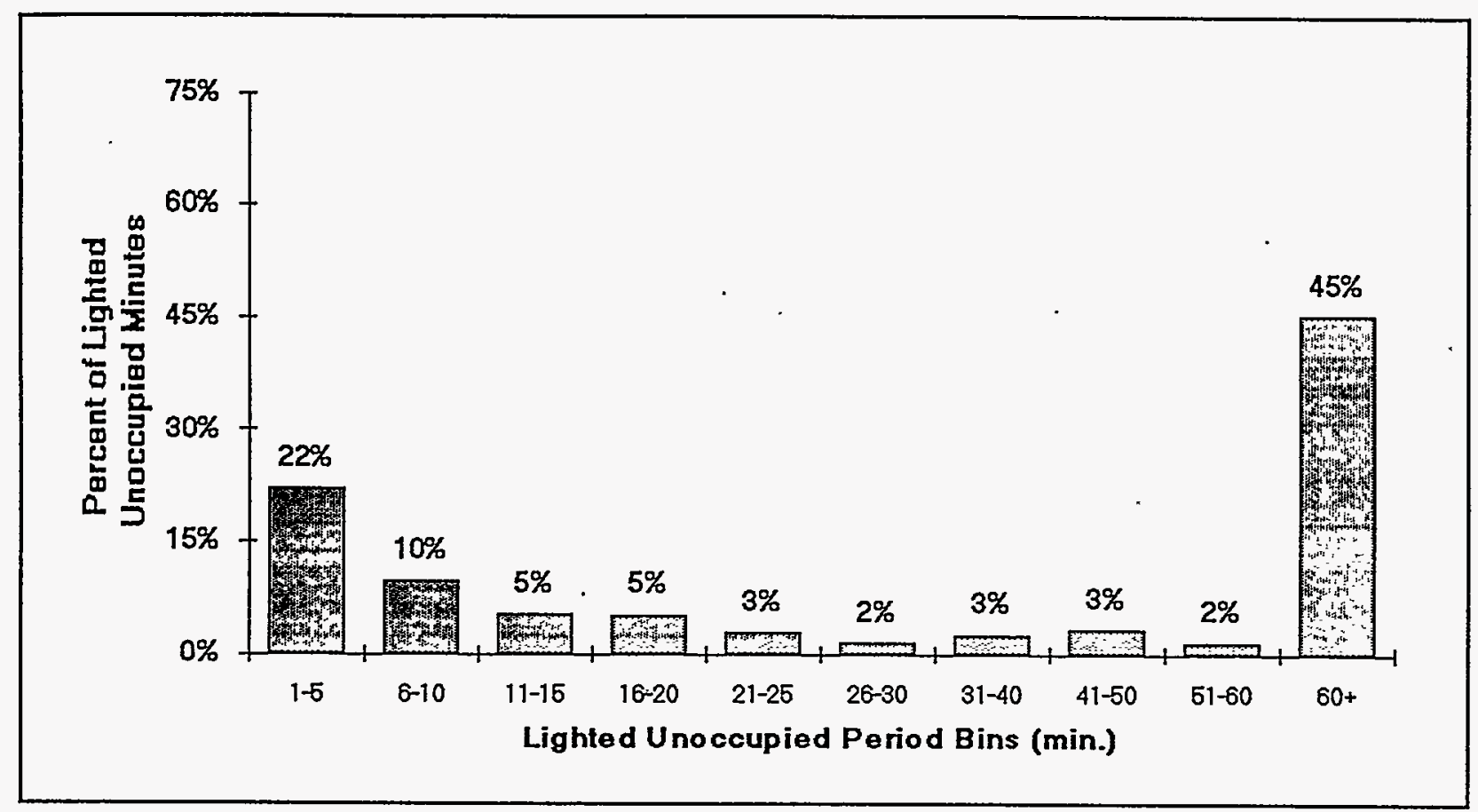

Figure 10. Percent of lighted unoccupied minutes for Copy/Mail room

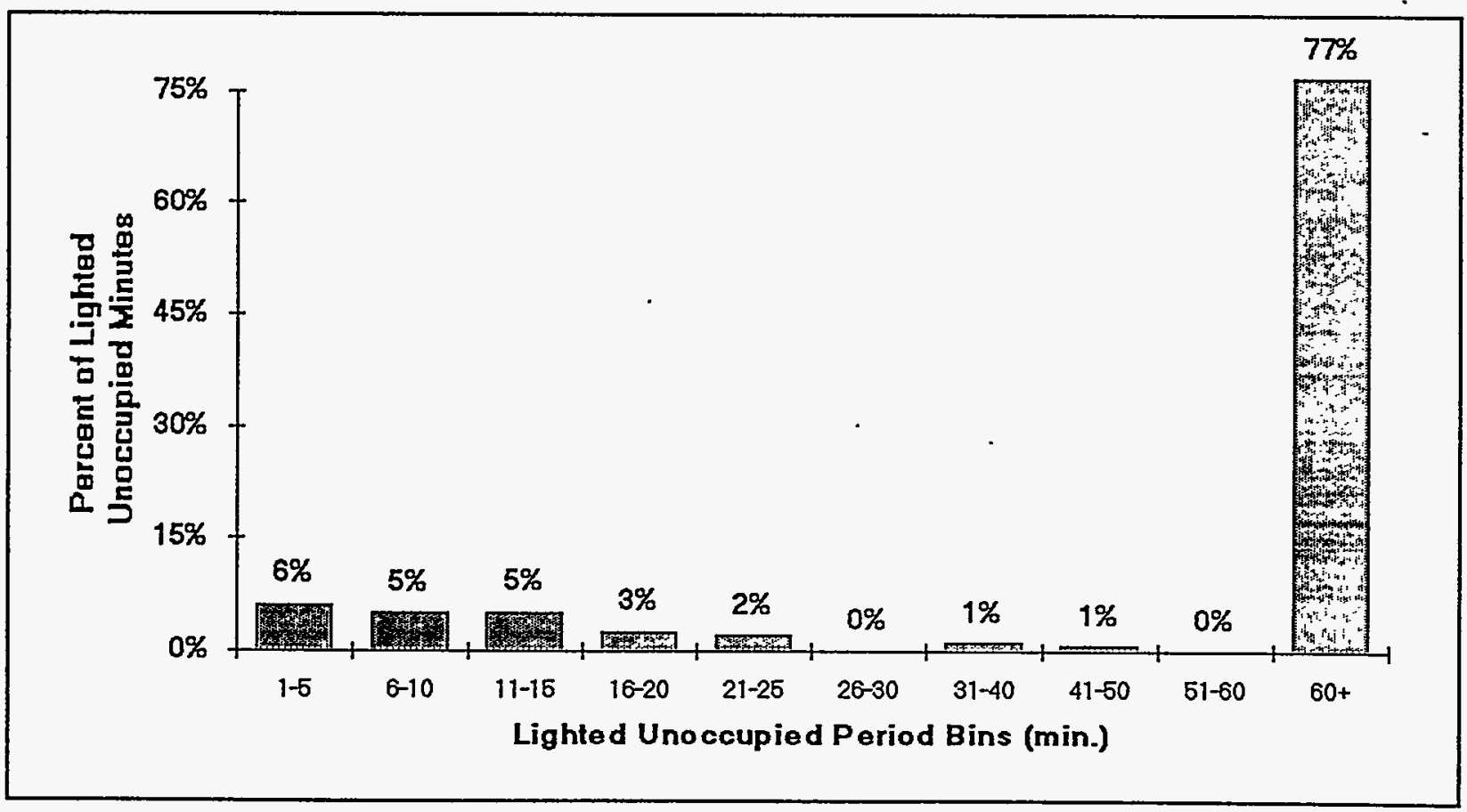

Figure 11. Percent of Lighted Unoccupied Minutes for Restroom 
The copy/mail room distribution is different than the managerial staff distribution but ultimately. has the same effect on savings. Copy/mail room spaces naturally experience long and short periods of unoccupancy while restrooms are dominated by very large periods of unoccupancy. These large periods of unoccupancy indicate that little additional savings will results from better timer adjustment.

The longer the unoccupied period, the less effect the length of the time delay has on the potential savings. Typically, when an occupancy sensor is installed, the time delay is left at the factory setting of 10 to 20 minutes. Resetting the time delay as low as possible when the occupancy sensor is installed is worthwhile, especially for technical staff offices. However, caution should be used to avoid setting the timer so low that lights are turned off on occupants. This situation can result in poor technology acceptance and no savings. The percent of potential savings associated with the five different time-delay settings for all six of the monitored spaces are shown in Table 4. Figure 12 presents the same information graphically and includes a theoretical 0 -minute setting, for which the potential savings would be $100 \%$ for all six spaces.

Table 4. Percent of Potential Savings at Various Time Delay Settings

\begin{tabular}{lccccc} 
Space or Occupant & $\begin{array}{c}\text { 2-Min } \\
\text { Setting }\end{array}$ & $\begin{array}{c}\text { 5-Min } \\
\text { Setting }\end{array}$ & $\begin{array}{c}\text { 10-Min } \\
\text { Setting }\end{array}$ & $\begin{array}{c}\text { 15-Min } \\
\text { Setting }\end{array}$ & $\begin{array}{c}20-\text { Min } \\
\text { Setting }\end{array}$ \\
\hline Technical Staff No. 1 & $76 \%$ & $50 \%$ & $24 \%$ & $8 \%$ & $3 \%$ \\
Technical Staff No. 2 & $64 \%$ & $45 \%$ & $29 \%$ & $20 \%$ & $13 \%$ \\
Managerial No. 1 & $80 \%$ & $67 \%$ & $53 \%$ & $44 \%$ & $36 \%$ \\
Managerial No. 2 & $84 \%$ & $72 \%$ & $59 \%$ & $49 \%$ & $41 \%$ \\
Copy/Mail Room & $78 \%$ & $65 \%$ & $55 \%$ & $50 \%$ & $46 \%$ \\
Restroom & $93 \%$ & $86 \%$ & $79 \%$ & $75 \%$ & $73 \%$
\end{tabular}
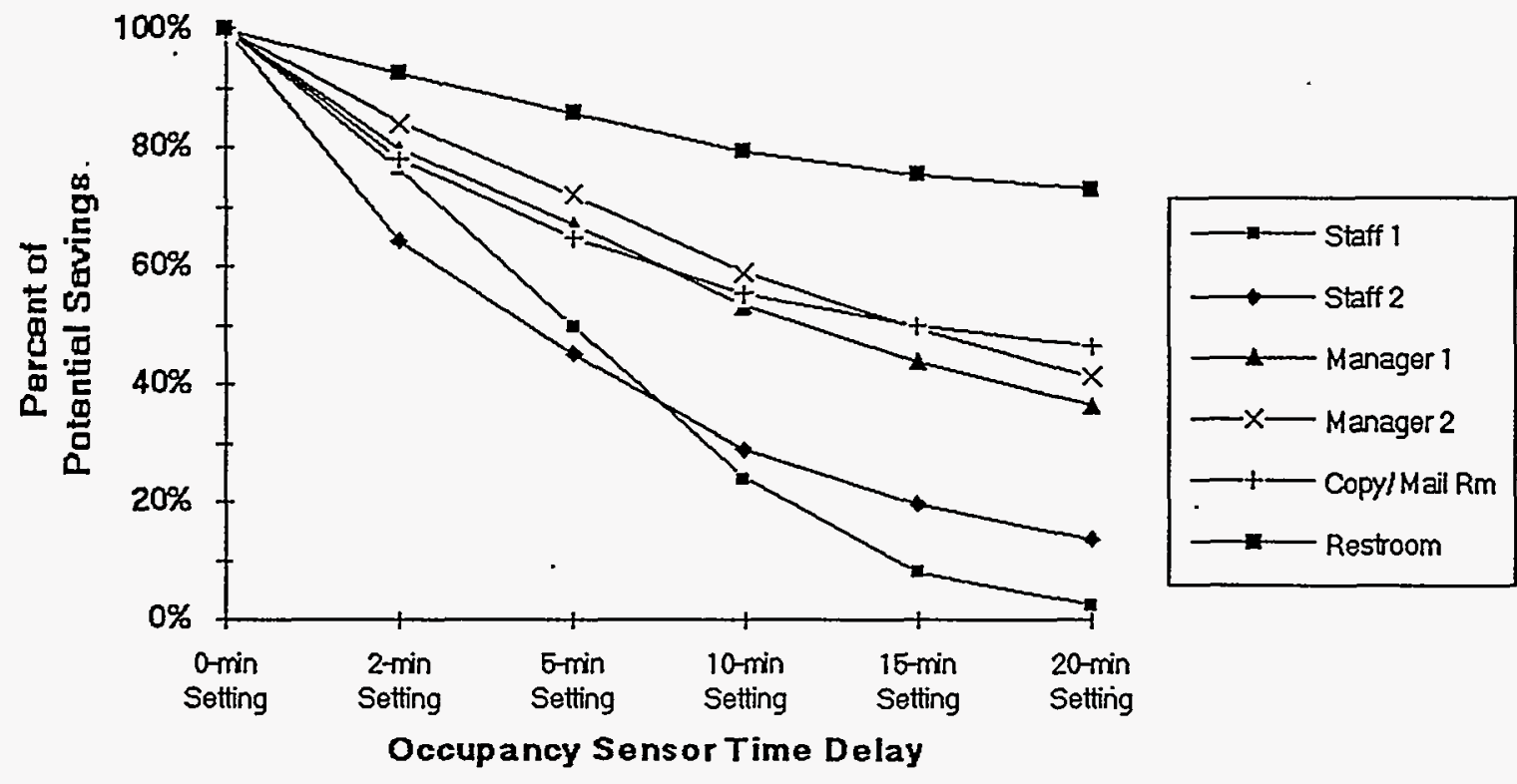

Figure 12. Percent of Potential Savings for Spaces at Various Time Delay Settings 
The six data sets shown in Figure 12 form three groupings representing different savings potential depending on the space or occupant type. The highest potential percentage increase of savings is available by adjusting timers in technical staff offices followed by managerial staff offices and copy/mail rooms. The least increased savings from timer adjustment is found in restrooms.

The effects shown closely follow generally expected effects and are considered representative. Because monitoring was done in only six spaces in one building, it is problematic to extrapolate these results to all office building spaces. Additional monitoring at several other locations would result in a better understanding of the effect of the time delay on different spaces and occupant types.

\section{Conclusions}

The results of this analysis provide useful information for assessing the cost-effective application of occupancy sensor controls in building spaces. The types and quantity of spaces that will benefit from this technology depend primarily on the function of each building space and its occupants, the amount of lighting wattage to be controlled, and the applicable utility rate. Specific conclusions drawn from the analysis are as follows:

- An important factor in the level of wasted-light hours in unoccupied spaces is the perceived ownership of the building space. Conference, training, library, and storage spaces tend to be temporarily owned by an individual or organization, and lights are generally turned off whenthe occupants leave the space. Copy rooms, lunchrooms, unoccupied labs, and restrooms are generally owned by everyone, and therefore, lights are more likely to be left on for the next occupant.

- More than one permanent occupant in an occupied space tends to decrease the wasted-light hours (approximately $13 \%$ fewer in technical staff and $10 \%$ fewer in administrative staff). This decrease is attributed to the staggered use of a space associated with multiple occupancy.

- Setting the timer control on a sensor device below the normal factory setting of $10+$ minutes can have a significant effect on the number of wasted-light hours saved (up to 39\% more if set to 3 minutes).

- The availability of daylight in a building space does not appear to have any noticeable effect on the quantity of wasted-light hours in occupied or unoccupied spaces.

Companion issues to occupancy control exist that can have a major effect on lighting energy use. These issues include daylighting control, lighting technology upgrade, and appropriate lighting reduction. These issues are not addressed as part of this analysis, but should be considered for future study and consideration with occupancy lighting control.

\section{References}

1. Maniccia, D., and Luan, X. 1994. Methods for assessing the maintained and initial detection performance of occupancy sensors. $J$ of The IES 23(no. 2): 108-15.

2. Stolshek, J.D., and Koehring, P.A., Jr. 1984. Ultrasonic technology provides for control of lighting. IEEE Transactions on Industry Applications IA-20(no. 6): 1564-72. 
3. Dagle, J.E. 1992. A field demonstration of energy conservation using occupancy sensor lighting control in equipment rooms. PNL-8320, Pacific Northwest Laboratory; Richland, WA. Springfield, Virginia: NTIS.

4. Jankowski, W. 1993. Occupancy sensors yield 25-75\% energy savings. Facilities Design and Management 12(no. 4): 25.

5. DeLeo, D. 1986. Sensors light the way from security to energy savings. Energy Management Technology 10(no. 1): 48-9. 